\section{Study of the histological profile of papillary thyroid carcinomas associated with Hashimoto's thyroiditis}

\author{
Estudo do perfil histológico de carcinomas papilíferos \\ de tireoide associados à tireoidite de Hashimoto
}

Maria Isabel Cunha Vieira Cordioli', Adriano Namo Cury ${ }^{\prime}$, Adriana Oliveira Nascimento ${ }^{2}$, Ana Karine de Oliveira ${ }^{2}$, Murilo Mello ${ }^{3}$, Mauro Ajaj Saieg ${ }^{2}$

\begin{abstract}
Objective: To investigate the association between the histological parameters of papillary thyroid cancer (PTC) and the presence of Hashimoto's thyroiditis (HT). Materials and methods: Histological samples from patients with PTC were reviewed by an endocrine pathologist. The following parameters were analyzed: presence of concomitant HT, multifocality, presence of nodal metastasis, tumor size, vascular invasion, perineural infiltration, histological variant, and pathological staging. Clinical data included gender and age at the time of the diagnosis. Results: A total of 94 cases of PTC were reviewed. There was a predominance of women $185.1 \%$ vs. $14.9 \%$ ) and median age at presentation was 45.13 years. The presence of HT was significantly associated with greater occurrence of multifocal tumors $(p=0.004)$, early pathological stage $(p=0.02)$, and smaller tumor size $(p=0.025)$. Conclusions: Patients with PTC associated with HT had significantly smaller tumors, more often multifocal and in an earlier stage than their counterparts without HT. A better understanding of the immune response involved in these tumors may be useful for future strategies on the prevention and for the development of new therapeutic approaches for this group of neoplasms. Arq Bras Endocrinol Metab. 2013;57(6):445-9
\end{abstract}

\section{Keywords}

Thyroid cancer; Hashimoto disease; prognosis

\section{RESUMO}

Objetivo: Investigar a associação entre parâmetros histológicos do carcinoma papilífero da tireoide (CPT) e a presença de tireoidite de Hashimoto (TH). Materiais e métodos: Amostra de tecidos de CPT foi revista por um médico patologista. Os seguintes parâmetros foram avaliados: presença de TH concomitante, multicentricidade, metástase linfonodal, tamanho tumoral, invasão vascular, infiltração perineural, variante histológica e estadiamento patológico. Os dados clínicos incluíam gênero e idade ao diagnóstico. Resultados: Um total de 94 casos de CPT foi revisto. Houve predomínio do sexo feminino $(85,1 \%$ vs. $14,9 \%)$ e a idade média de apresentação foi de 45,13 anos. A presença de TH foi associada a maior ocorrência de tumores multifocais $(p=$ $0,004)$, estágios iniciais de estadiamento $(p=0,02)$ e tumores menores $(p=0,025)$. Conclusão: 0 CPT associado a TH apresentou-se com menor dimensão, maior ocorrência de multifocalidade e em estadiamentos mais iniciais do que os casos de CPT sem TH associada. Um melhor entendimento da resposta imune envolvida nesses tumores pode ser útil para estratégias futuras de prevenção e para o desenvolvimento de novas abordagens terapêuticas para esse tipo de neoplasia. Arq Bras Endocrinol Metab. 2013;57(6):445-9

\section{Descritores}

Câncer de tireoide; doença de Hashimoto; prognóstico
${ }^{1}$ Endocrine Division, Santa Casa Medical School, São Paulo, SP, Brazil ${ }^{2}$ Pathology Division, Santa Casa Medical School, São Paulo, SP, Brazil ${ }^{3}$ Physiology Division, Santa Casa Medical School, São Paulo, SP, Brazil
Correspondence to:

Maria Isabel Cunha Vieira Cordioli Rua Pedro de Toledo, 669, $11^{\circ}$ andar 04039-032 - São Paulo, SP, Brazil isabelcordioli@gmail.com

Received on Feb/15/2013 Accepted on Apr/22/2013 


\section{INTRODUCTION}

$\mathrm{H}$ ashimoto's thyroiditis (HT), also known as chronic lymphocytic thyroiditis, is the most common autoimmune thyroid disease and the main cause of hypothyroidism in the world (1). The relationship between HT and papillary thyroid cancer (PTC), the most common type of thyroid neoplasm, was first shown by Dailey and cols. in 1955 (2), but still remains a controversial issue $(1,3-6)$.

The reported rate of coexistence of HT in patients with PTC ranges from $0.3 \%$ to $38 \%$ (7-8). The molecular pathways involved in this association have not yet been fully clarified, and the possibility that HT is a premalignant lesion also remains controversial (9). The RET/PTCI and RET/PTC3 rearrangements, classically seen in PTC, have also been described in patients with HT $(10,11)$, together with a higher prevalence of $p 63$ expression (10). On the other hand, the prevalence of the $B R A F^{\mathrm{V} 600 \mathrm{E}}$ mutation, which is associated with a poor prognosis in PTC, was detected in a higher frequency in patients without associated HT (11). Other proposed markers of thyroid malignancies include the HBME-1 (12), GAL3 (13), and specific cytokeratins, such as CK19 (10). However, the relevance of these markers in HT is still under debate, since their occurrence was also observed in others benign lesions, although with a lower prevalence than in PTC (14).

Another controversial issue with conflicting results in the literature is the prognosis of PTC-associated HT (67,11). A meta-analysis by Singh and cols. showed an improved disease-free survival rate in patients with coexistent HT. However, when reporting their own series, the authors did not find any statistical difference in disease-free survival of 388 PTC patients when associated with the coexistence of HT (5). In addition, recent studies reporting the association of histological parameters in PTC with the presence of HT also show controversial results (6-7).

The aim of the current study was to assess the rate of PTC-associated HT in our institution and to clarify whether the presence of HT in these cases of surgically treated PTC were significantly associated with histological and/or clinical parameters and disease staging.

\section{MATERIALS AND METHODS}

\section{Selection of patients}

A computerized search was performed in the electronic files of the Department of Pathology at Santa
Casa de São Paulo Hospital for cases of surgically excised thyroid glands with a diagnosis of PTC in a sevenyear period (2003-2009). Clinicopathological parameters were also retrieved from the reports and included gender, age at the time of the diagnosis, size of the tumor, multifocality, pathological staging (TNM) (15), and presence of nodal metastasis.

This study was submitted to and approved by the Ethics Committee in Research of Santa Casa de São Paulo Hospital.

\section{Histopathological review}

Cases were reviewed by an endocrine pathologist and the following histological features were analyzed: presence of concomitant HT, vascular invasion, perineural infiltration, and histological variant of PTC. HT was defined by a diffuse lymphocytic and plasma cell infiltrate with the presence of lymphoid follicles with reactive germinal centers, as well as occasional Hürthle cells (Figure 1) (6).
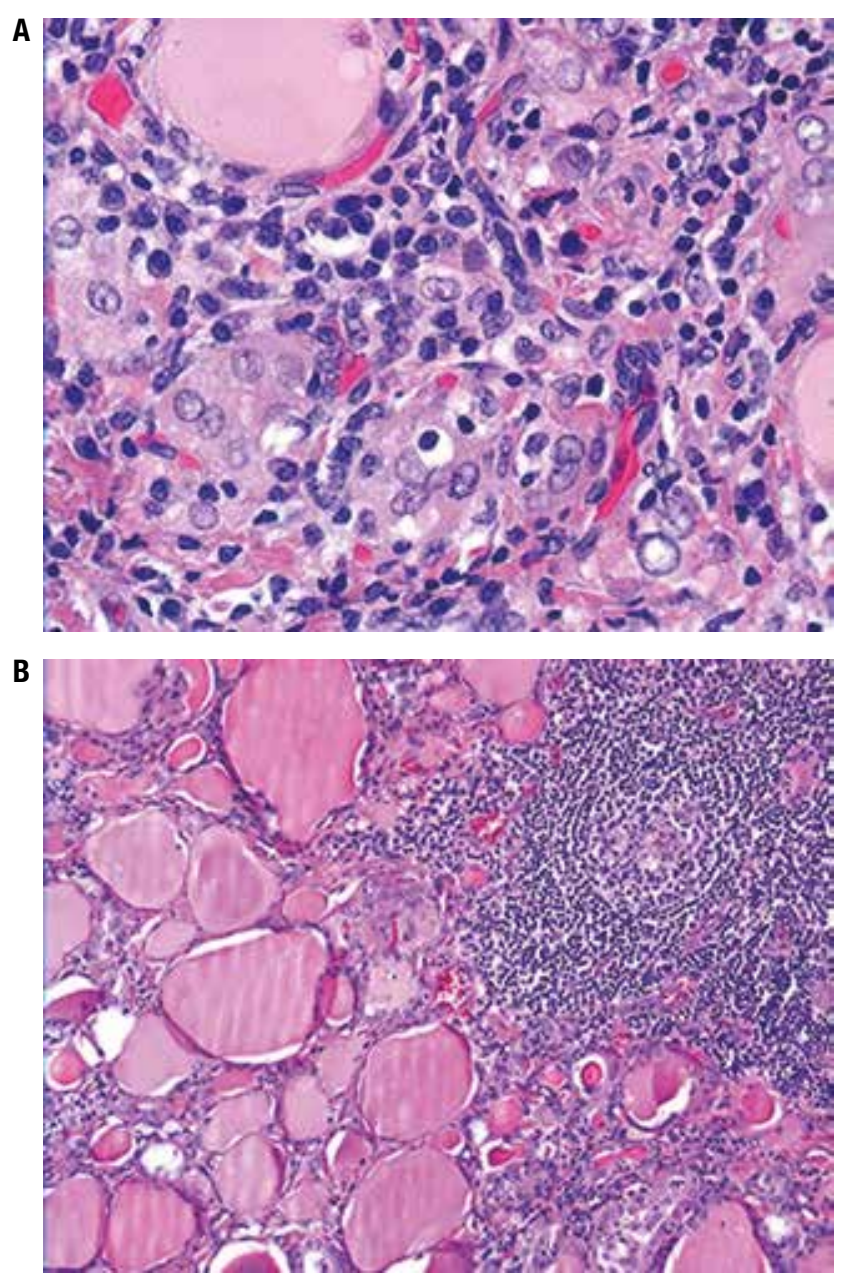

Figure 1 (A and B). H\&E section of HT. Note the lymphocyte infiltrate assuming a follicular architecture and lymphoepithelial lesions. 


\section{Statistical analysis}

Statistical analysis were performed using chi square test and Fisher's exact test for a single variable, with stepwise regression for multivariate analysis. Only variables with $\mathrm{p} \leq 0.200$ at the univariate analysis were included in the multivariate model. All potential confounding variables were considered. The level of significance was set to $5 \%$. Statistical analysis was performed with the aid of the SPSS v19.0 statistical package (SPSS Inc, Chicago, IL, USA).

\section{RESULTS}

A total of 94 cases of PTC from 94 patients were reviewed. There were 80 females $(85.10 \%)$ and 14 males (14.89\%). Median age at presentation was 45.13 years (range from 8-75 years). When subtyped by histology, 54 cases were exclusively classic PTC, 16 were represented by the follicular variant of PTC, 14 cases were mixed types (classic PTC and areas of follicular pattern), 4 were oncocytic, and 6 cases comprised of other rare subtypes of PTC ( 2 tall cell, 2 columnar cell, 1 diffuse sclerosing, and 1 macrofollicular). The median tumor size was $2.19 \mathrm{~cm}$ (range from $0.1-10 \mathrm{~cm}$ ). Eighteen cases $(19.14 \%)$ had multifocal tumors and metastases to lymph nodes were present in 25 cases (26.59\%). Vascular invasion and perineural infiltration were detected in $54(57.44 \%)$ and $23(24.46 \%)$ of the cases, respectively.

Tumors were also classified in two groups according to their pathological staging (pTNM): early stage (Tl/ T2) and late stage (T3/T4). According to this criteria, 49
(52.12\%) of the cases were early stage tumors and the remaining $45(47.87 \%)$ were classified as late stage disease.

\section{Association of HT with clinical and pathological parameters}

The summary of results of the association between the presence of HT and PTC is shown in Table 1. HT was present in $35(37.2 \%)$ of the cases and absent in the remaining $59(62.8 \%)$. Age at the initial diagnosis was not significantly different between the two groups ( 44.7 for HT absent $v$ s. 45.8 for HT present, $p=0.70$ ). There was no gender predisposition for the presence of PTC-associated HT. Females were predominant in both groups $(83.06 \%$ in HT absent $v$ s. $88.58 \%$ in HT present, respectively) and males corresponded to $16.94 \%$ of the cases in the HT absent and $11.42 \%$ of the cases in the HT present group, with no statistical difference $(p=0.46)$. Furthermore, no statistical association was seen between the presence of HT and vascular invasion $(p=0.13)$, perineural infiltration $(p=0.43)$ or lymph node metastasis $(p=0.73)$ (Table 1$)$.

Univariate analysis showed that tumor size was significantly smaller in patients with concomitant HT than in patients without HT $(1.56 \pm 1.30$ vs. $2.51 \pm 2.09)$ $(p=0.025)$ (Figure 2). Multifocal tumors were also significantly more common in patients with concomitant HT $(33 \%$ vs. $12 \%)(p=0.014)$ (Figure 3$)$, and these patients were also more frequently classified as having early stage tumors (T1/T2) $(65.71 \%$ vs. $44.06 \%)(p=0.046)$. Multivariate statistical analysis confirmed this association for all of the three parameters (Table 1).

Table 1. PTC clinicopathological parameters according to the presence or absence of HT

\begin{tabular}{|c|c|c|c|c|}
\hline & HT absent & HT present & $\begin{array}{c}p \text {-value } \\
\text { (univariate) }\end{array}$ & $\begin{array}{c}p \text {-value } \\
\text { (mulivariate) }\end{array}$ \\
\hline Number & $59(62.8 \%)$ & $35(37.2 \%)$ & & \\
\hline Age at diagnosis (year) & $44.7 \pm 14.7$ & $45.8 \pm 13.2$ & 0.70 & $\mathrm{~N} / \mathrm{T}$ \\
\hline Gender & & & 0.46 & $N / T$ \\
\hline Male & 10 (16.94\%) & $4(11.42 \%)$ & & \\
\hline Female & $49(83.06 \%)$ & $31(88.58 \%)$ & & \\
\hline Tumor size (cm) & $2.51 \pm 2.09$ & $1.56 \pm 1.30$ & 0.025 & 0.017 \\
\hline Tumor multifocality & $7(12 \%)$ & $11(33 \%)$ & 0.014 & 0.019 \\
\hline LN metastasis & $15(25.42 \%)$ & $10(28.57 \%)$ & 0.73 & $N / T$ \\
\hline Vascular invasion & $38(64.4 \%)$ & $16(45.71 \%)$ & 0.13 & 0.665 \\
\hline Perineural infiltration & $16(27.11 \%)$ & $6(17.14 \%)$ & 0.37 & $N / T$ \\
\hline TNM & & & 0.046 & $N / T$ \\
\hline $\mathrm{T} 1 / \mathrm{T} 2$ & $26(44.06 \%)$ & $23(65.71 \%)$ & & \\
\hline T3/T4 & 33 (55.93\%) & $12(34.28 \%)$ & & \\
\hline
\end{tabular}

$\mathrm{N} / \mathrm{T}$ : only variables with $\mathrm{p} \leq 0.200$ at the univariate analysis were included in the multivariate model; since T of TNM is highly related to tumor size, only tumor size was included in the multivariate analysis. In the multivariate analysis, only tumor size and the occurrence of multifocality remained in the model, which presented $r=0.340$ and $p=0.006$. 


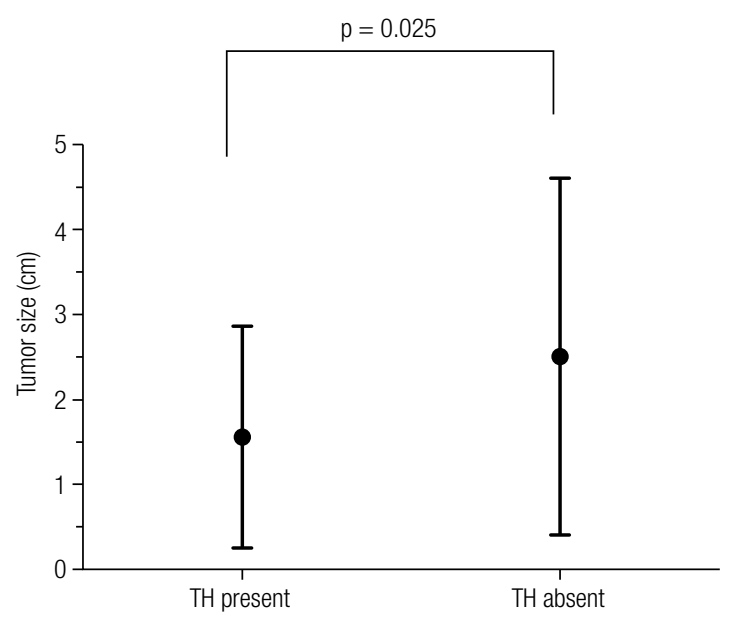

Figure 2. Tumor size according to the presence of Hashimoto's thyroiditis.

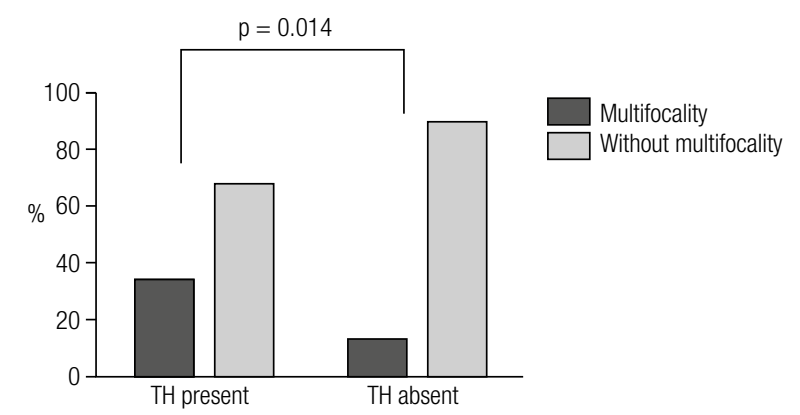

Figure 3. Prevalence of multifocality according to the presence of Hashimoto's thyroiditis.

\section{DISCUSSION}

Our current study shows that HT was seen in a great part of the PTCs and that it was statistically associated with tumor multifocality, early pathological staging, and small tumor size. The present results indicate the existence of a distinct group of neoplasms associated with HT, what may corroborate the hypothesis that immune response plays a major role in the onset of malignant neoplasms of the thyroid.

HT was a common finding in the event of PTC $(37.2 \%)$ in our study, which is in agreement with current literature (1,5-6). In a meta-analysis by Singh and cols. (5) it has been demonstrated that $\mathrm{HT}$ incidence is 2.77 higher in surgical specimens removed due to PTC than in cases of benign disease. Also, the association with HT was 1.89 times greater in patients with PTC than in patients with other thyroid neoplastic conditions. Women with HT have also been shown to be $30 \%$ more likely to have coexisting PTC in comparison with patients without HT (1).

The relationship between PTC and HT remains a matter of controversy despite being investigated over the past several decades. It is unclear if the presence of HT is second- arily induced by thyroid cancer as a host immune response, or whether HT predisposes the development of PTC (7). It has also been debated in the literature if the presence of $\mathrm{HT}$ is associated with certain PTC features of prognostic value.

The occurrence of multifocal tumors in our study was significantly higher among patients with concomitant HT, a similar result to that described by Asanuma and cols. (9). Several hypotheses could explain this association, such as a change in the environment of the whole gland due to the inflammation, which might contribute to cancer progression (16), or a protective action of autoimmunity against PTC.

The finding of multifocality among our HT-associated PTC is especially relevant since the occurrence of multicentricity is one of the features associated with a poor prognosis in patients with PTC in the clinical practice (17). The finding of a feature associated with poor prognosis in the occurrence of PTC concomitant with HT contrasts with previous studies that suggested better prognosis of this type of cancer in association with lymphocytic thyroiditis. Previous studies have suggested a relationship between lymphocytic infiltration (LI) and tumor features, leading to low frequency of recurrence (18) and an improvement in disease-free survival (19). Similar findings were also observed when considering diffuse and peritumoral infiltration separately $(20)$. On the other hand, Del Rio and cols. have showed in a recent study that the association of PTC with HT did not modify the aggressiveness of the tumor (21).

These conflicting results about the influence of HT in prognostic features of PTC may be explained by the fact that different immune responses can be associated with PTC. A recent study considered the existence of two types of such immune response: lymphocytic thyroiditis and tumor associated lymphocytes (TAL) in the absence of thyroiditis. The occurrence of TAL is defined by the presence of lymphocyte infiltration (LI) aggregate to the tumor (intratumoral or peritumoral) (22). Besides, different lymphocytes cells can be found associated with the tumors. The $\mathrm{CD}^{+} \mathrm{T}$ cells play a central role in immune protection, and naive $\mathrm{CD} 4^{+} \mathrm{T}$ cells can be differentiated into four distinct effector cells: Th1, Th2, Th17, and Tregs (22). These types of cells have different mechanisms of action, and the prevalence of one of them may be the responsible for the conflicting results related to the effect of LI in PTC that were found in the literature. Previous studies have also shown that an increased frequency of regulatory $\mathrm{T}$ cells (Tregs) in LI is associated with poor prognosis of dif- 
ferent types of cancer $(23,24)$ and, recently, this association was also found in PTC. French and cols. suggest that Treg frequency may be a useful diagnostic marker in determining PTC prognosis, and it may also be a target for future therapies (22). Further studies that aim to qualify the type of predominant response in cases with HT-associated PTC may be able to clarify this matter.

The results of a better pathological stage among HT-associated PTC patients is in agreement with Huang Bie Yu and cols. (7) as well, who have observed a higher percentage of patients in stage IV in non-HT PTC. Once more, different results in the literature regarding LI and PTC prognosis may also be explained by the existence of different immune responses associated with PTC, as previously mentioned.

Our present study did not find any significant difference between patients with or without HT regarding vascular invasion, perineural infiltration or lymph node metastasis, which may be due to a small number of patients with these features, perhaps the main limitation of our study. In order to confirm or discard these findings, future studies with a greater number of tumor samples should be carried out.

The current findings of specific histological characteristics present in HT-associated PTC signalize a potential subset of thyroid papillary neoplasms, which can benefit from immune-based therapies. A better understanding of the role of the immune system in the pathophysiology of PTC can be of great value to the development of future strategies for the prevention of tumor onset and to the application of alternative forms of targeted therapies for this type of cancer.

Acknowledgments: we would like to thank Dr. Manuel Sobrinho Simões and Paula Soares for the useful discussion in the beginning of this work.

Disclosure: no potential conflict of interest relevant to this article was reported.

\section{REFERENCES}

1. Repplinger D, Bargren A, Zhang YW, Adler JT, Haymart M, Chen $\mathrm{H}$. Is Hashimoto's thyroiditis a risk factor for papillary thyroid cancer? J Surg Res. 2008;150(1):49-52.

2. Dailey ME, Lindsay S, Skahen R. Relation of thyroid neoplas$\mathrm{ms}$ to Hashimoto disease of the thyroid gland. AMA Arch Surg. 1955;70(2):291-7.

3. Anil C, Goksel S, Gursoy A. Hashimoto's thyroiditis is not associated with increased risk of thyroid cancer in patients with thyroid nodules: a single-center prospective study. Thyroid. 2010;20(6):601-6.

4. Mazokopakis EE, Tzortzinis AA, Dalieraki-Ott El, Tsartsalis AN, Syros PK, Karefilakis CM, et al. Coexistence of Hashimoto's thyroiditis with papillary thyroid carcinoma. A retrospective study. Hormones (Athens). 2010;9(4):312-7.
5. Singh B, Shaha AR, Trivedi H, Carew JF, Poluri A, Shah JP. Coexistent Hashimoto's thyroiditis with papillary thyroid carcinoma: impact on presentation, management, and outcome. Surgery. 1999;126(6):1070-6; discussion 6-7.

6. Gul K, Dirikoc A, Kiyak G, Ersoy PE, Ugras NS, Ersoy R, et al. The association between thyroid carcinoma and Hashimoto's thyroiditis: the ultrasonographic and histopathologic characteristics of malignant nodules. Thyroid. 2010;20(8):873-8.

7. Huang BY, Hseuh C, Chao TC, Lin KJ, Lin JD. Well-differentiated thyroid carcinoma with concomitant Hashimoto's thyroiditis present with less aggressive clinical stage and low recurrence. Endocr Pathol. 2011;22(3):144-9.

8. Kim HS, Choi YJ, Yun JS. Features of papillary thyroid microcarcinoma in the presence and absence of lymphocytic thyroiditis. Endocr Pathol. 2010;21(3):149-53.

9. Asanuma K, Sugenoya A, Kasuga Y, Itoh N, Kobayashi S, Amano $J$. The relationship between multiple intrathyroidal involvement in papillary thyroid carcinoma and chronic non-specific thyroiditis. Cancer Lett. 1998;122(1-2):177-80.

10. Nasser SM, Pitman MB, Pilch BZ, Faquin WC. Fine-needle aspiration biopsy of papillary thyroid carcinoma: diagnostic utility of cytokeratin 19 immunostaining. Cancer. 2000;90(5):307-11.

11. Kim SK, Song KH, Lim SD, Lim YC, Yoo YB, Kim JS, et al. Clinical and pathological features and the BRAF(V600E) mutation in patients with papillary thyroid carcinoma with and without concurrent Hashimoto thyroiditis. Thyroid. 2009;19(2):137-41.

12. Sack MJ, Astengo-Osuna C, Lin BT, Battifora H, LiVolsi VA. HBME1 immunostaining in thyroid fine-needle aspirations: a useful marker in the diagnosis of carcinoma. Mod Pathol. 1997;10(7):668-74.

13. Prasad ML, Pellegata NS, Huang Y, Nagaraja HN, de la Chapelle A, Kloos RT. Galectin-3, fibronectin-1, CITED-1, HBME1 and cytokeratin-19 immunohistochemistry is useful for the differential diagnosis of thyroid tumors. Mod Pathol. 2005;18(1):48-57.

14. Nasr MR, Mukhopadhyay S, Zhang S, Katzenstein AL. Absence of the BRAF mutation in HBME1+ and CK19+ atypical cell clusters in Hashimoto thyroiditis: supportive evidence against preneoplastic change. Am J Clin Pathol. 2009;132(6):906-12.

15. Greene FL. AJCC cancer staging manual. 6th ed./editors: Frederick L. Greene, et al. (ed.) New York; London: Springer; 2002.

16. Muzza M, Degl'Innocenti D, Colombo C, Perrino M, Ravasi E, Rossi S, et al. The tight relationship between papillary thyroid cancer, autoimmunity and inflammation: clinical and molecular studies. Clin Endocrinol (Oxf). 2010;72(5):702-8.

17. Cooper DS, Doherty GM, Haugen BR, Kloos RT, Lee SL, Mandel SJ, et al. Revised American Thyroid Association management guidelines for patients with thyroid nodules and differentiated thyroid cancer. Thyroid. 2009;19(11):1167-214.

18. Matsubayashi S, Kawai K, Matsumoto Y, Mukuta T, Morita T, Hirai $\mathrm{K}$, et al. The correlation between papillary thyroid carcinoma and lymphocytic infiltration in the thyroid gland. J Clin Endocrinol Metab. 1995;80(12):3421-4.

19. Gupta S, Patel A, Folstad A, Fenton C, Dinauer CA, Tuttle RM, et al. Infiltration of differentiated thyroid carcinoma by proliferating lymphocytes is associated with improved disease-free survival for children and young adults. J Clin Endocrinol Metab. 2001;86(3):1346-54.

20. Villagelin DG, Santos RB, Romaldini JH. Is diffuse and peritumoral lymphocyte infiltration in papillary thyroid cancer a marker of good prognosis? J Endocrinol Invest. 2011;34(11):e403-8.

21. Del Rio P, Cataldo S, Sommaruga L, Concione L, Arcuri MF, Sianesi $M$. The association between papillary carcinoma and chronic lymphocytic thyroiditis: does it modify the prognosis of cancer? Minerva Endocrinol. 2008;33(1):1-5.

22. French JD, Weber ZJ, Fretwell DL, Said S, Klopper JP, Haugen BR. Tumor-associated lymphocytes and increased FoxP3+ regulatory $\mathrm{T}$ cell frequency correlate with more aggressive papillary thyroid cancer. J Clin Endocrinol Metab. 2010;95(5):2325-33.

23. Bates GJ, Fox SB, Han C, Leek RD, Garcia JF, Harris AL, et al. Quantification of regulatory $T$ cells enables the identification of high-risk breast cancer patients and those at risk of late relapse. $J$ Clin Oncol. 2006;24(34):5373-80.

24. Barnett B, Kryczek I, Cheng P, Zou W, Curiel TJ. Regulatory T cells in ovarian cancer: biology and therapeutic potential. Am J Reprod Immunol. 2005;54(6):369-77. 